$\begin{array}{ll}\text { Türkiye Tarımsal Araştırmalar Dergisi } & \begin{array}{l}\text { Turk J Agric Res } \\ \text { http://dergi.sirt.edu.tr }\end{array} \\ \text { (2015) 2: 114-117 } \\ \text { TÜTAD } \\ \text { ISSN: 2148-2306 }\end{array}$

\title{
The Effect of Different Pollination Methods on Seed Yield and Germination Features in Stevia rebaudiana Bertoni
}

\author{
Yaşar ÖZYIĞİT ${ }^{1}$, Esra UÇAR $^{2 *}$, Kenan TURGUT ${ }^{3}$ \\ ${ }^{1}$ Akdeniz University, Korkuteli Vocational School, Horticulture Programme, Antalya, TURKEY \\ ${ }^{2}$ Cumhuriyet University, Sivas Vocational School, Organic Agriculture Programme, Sivas, TURKEY \\ ${ }^{3}$ Akdeniz University, Faculty of Agriculture, Department of Field Crops, Antalya, TURKEY
}

\begin{tabular}{ll}
\hline \multicolumn{1}{c}{ Received: 15.07 .2015} & Accepted: 18.08 .2015 \\
\hline${ }^{*}$ Correspondence: eucar@cumhuriyet.edu.tr &
\end{tabular}

\begin{abstract}
Pollination is a prerequisite system for reproductive of many plants and it is more important in self-compatible plants. Since, these plants need other flowers pollen for flower fertilization and seed production. In this study, the effects of different pollination methods (open/cross pollination, self-pollination with hand and control) on some features associated with seed production in Stevia rebaudiana were investigated. Stevia which belongs to the Asteraceae family and is used as sweetener has a self-incompatibility problem. In the experiment, ten plants which were planted in a row were covered with net in the field condition and five of them were selfed with hand pollination and remaining 5 plants were left as it is. Furthermore, five uncovered plants were left to cross-pollination by insects. At the end of the experiment, seed yield per plant, 1000 seed weight, black/filled seed rate, number of day to first germination and germination rate were determined in harvested seeds. According to the results, cross-pollination was more superior in respect to all features in Stevia. This status shows that insect population (especially bee) must be present in Stevia fields for successful seed production.
\end{abstract}

Keywords: Bee, self pollination, self-compatible, sweet herb, cross pollination

\section{Introduction}

Stevia rebaudiana (Bert.) is a perennial and subshrub herb of the Asteraceae family and originated from South America. It has been used as sweetener and herbal medicine in Paraguay for thousands of years, and it is cultivated in many countries such as Japan, China, India, Taiwan, Korea, Mexico, USA, Thailand, Malaysia, Indonesia, Australia etc. The sweetness of leaf extract of Stevia is 300 times sweeter than sugar cane (Ramesh et al., 2007). Stevia has more than 180 species, but the sweetest extract is obtained from Stevia rebaudiana because this species has sweet diterpenoid glycoside which 200-300 times sweeter than sucrose. The most important feature of sweet herb is its zero calorie sweeteners for diabetics, dieters and people who care about their health (Kumuda, 2006).

Sweet herb can be propagated both seed and cuttings (Brandle et al., 1998). However, the germination ability of the seeds are generally low, sometimes germination does not happen. Generally, infertile seeds are usually pale or clear and fertile seeds are dark coloured (Yadav et al., 2011). Immature seed harvest causes very low seed germination. Also, Madan et al. (2010) reported that environmental conditions are important in seed production of Stevia; for instance, intensive rainfalls reduce seed yield and germination ability of seed. The most important problem about seed production in Stevia is self-incompatibility of the flowers and so it needs cross-pollination for seed production (Midmore and Rank, 2002).

Pollination is a system which provides transfer of genetic information between plants through pollen (Hein, 2009). Pollen production occurs in abundant male organs and must move to stigma for fertilization (Delaplane and Mayer, 2000). Especially, self-incompatible plant species need pollinators, for seed production (Paalhaar et al., 
2008). In general, five pollination mechanisms; wind (anemophily), water (hydrophily), birds (ornithophily), mammals (zoophily), and insects (entomophily) are occurred in plants (Isagi, 2011 ). Wind pollination is widespread in the plant communities (Ingrouille and Eddie, 2006), but there are some negative properties of wind pollination, for instance, wind pollination is less abundant in the way of pollen deposition on homologous stigmas compared with animalpollinated plants (Munguía-Rosas et al., 2011). Also, sometimes, pollens can be too heavy for wind pollination (Delaplane and Mayer, 2000). Therefore, insect pollination is the most common pollination method (Cerena, 2004). At present, honeybees are the most important pollinator of flowering plants on earth (Corbet et al., 1991; Klein et al., 2009).

Pollination is an obligatory system for sexual reproduction of many plants and it is very important for food production and human livelihood (Hein, 2009). Absence of the pollinators will cause extinction of many plant species and cultivation of many crops would be impossible (Brading et al., 2009). Inadequate pollination will cause not only reduced yield but also low quality of production. Also, primary production of natural ecosystems is reduced in case of inadequate pollination (Corbet et al., 1991; Klein et al., 2009). To produce seeds with high germination rate is possible based on pollination methods (Midmore and Rank, 2002; Yadav et al., 2011).

The objective of this study was to investigate the effect of different pollination methods on seed yield and germination features in Stevia.

\section{Materials and Methods}

This study was conducted in both field and laboratory conditions. The pollinated stevia plants were grown in the Department of Field Crops, Faculty of Agriculture, Akdeniz University, in Augst-September 2012. Firstly, 200 Stevia seedlings were planted to the soil with a spacing of $65 \mathrm{~cm} \times 45 \mathrm{~cm}$. At planting, di ammonium phosphate fertilizer was applied to the soil based on $10 \mathrm{~kg} \mathrm{da}^{-1}$ phosphorus. The flowering of sweet herb was found better in a short day condition (Brandle et al., 1998). Thus, after first cutting, plants were left to produce seeds in a short day condition. Also, ammonium nitrate fertilizer was applied as pure $10 \mathrm{~kg} \mathrm{da}^{-1}$ nitrogen to the plot just after the harvest.

The experiment was conducted as a randomized complete design method with five replicates. Fifteen plants were selected randomly at the flower budding stage in different part of the plot and ten randomly selected plants were covered with nets (Width: $75 \mathrm{~cm} \mathrm{x} 75 \mathrm{~cm}$, Height: $100 \mathrm{~cm}$ ) in order to obstruct insect activity. Five plants covered with nets were self-pollinated with hand and hand pollination process was continued during flowering period; remaining 5 plants were left for self-pollination as controls. Also, five uncovered plants were left to cross-pollination by insects, and intensive bee and insect activities were observed in these plants. When seeds were matured, they were harvested by hand and kept in glass jars.

For laboratory experiments, seeds obtained from field grown plants were weighed and seed yield per plant was determined for each plant. After that, 1000 seeds were counted as 3 replicates and then each replicate was weighed. Furthermore, dark coloured/filled and pale/hollow seeds were separated from each replicate and counted in order to find out percentage of dark coloured/filled seeds. For the germination study, each treatment consisted of 3 repetitions of 100 seeds were counted and placed into petri dishes which contain blotting paper wetted with distilled water. After that, petri dishes were closed and wrapped with paraffin and placed in an incubator with the temperature of $24^{\circ} \mathrm{C}$ and light. First seed germination of each petri dish was considered as first germination day. Germinated seeds were counted in each petri dish after 15 days in incubation and germination rate was determined for each treatment.

All data were expressed as mean \pm standard deviation. Analysis of variance was performed by the software SAS. Significant differences between means were determined by Duncans multiplerange test. A significant difference was considered at the level of $\mathrm{P}<0.05$.

\section{Results and Discussions}

According to the results, open (cross) pollinated plants gave higher values than others for all features (Table 1).

Seed yield per plant was ranged from $2.064 \mathrm{~g}$ to $3.636 \mathrm{~g}$ and significantly varied between crosspollinated and others. The highest seed yield per plant was obtained from cross pollinated plants. Seed yield of self-pollinated and closed/control plants was found to be very close to each other. While the highest 1000 seed weight $(0.398 \mathrm{~g})$ was determined in cross pollinated plants, other two gave similar results. Madan et al. (2010) were recorded that 1000 seeds weight in Stevia were ranged from $0.15 \mathrm{~g}$ to $0.30 \mathrm{~g}$. Also, Midmore and Rank (2002) reported that Stevia seeds were very 
small and 1000 seeds weight were varied between $0.3 \mathrm{~g}$ and $1.0 \mathrm{~g}$. These reports support the results of present study.

Dark coloured/filled seed rates were varied significantly among three treatments. The highest rate was found in cross pollinated plants with $78 \%$ and followed by self-pollinated plants with $48 \%$. The lowest dark coloured/filled seed rate (9\%) was obtained from closed/control plants. Yadav et al. (2011) were report that fertile seeds are usually dark coloured, whereas infertile seeds are usually pale or clear in stevia.

First germination was observed in cross pollinated seeds after 3 days in culture and followed by self-pollinated seeds after 4 days in culture. On the other hand, first germination of control seeds was occured after 6 days in culture. The highest germination rate was recorded in cross pollinated seeds with $49 \%$ and followed by selfpollinated seeds with $15.4 \%$. However, closed/control seeds were gave the lowest rate as $2.4 \%$.

As many self-incompatible plants, Stevia also needs cross pollination with insects particularly bees for seed set. Naturally, bees visit plant flowers in order to collect nectar and pollen, and pollens clinging to bee's body transfer from one flower to other flower and thus pollination occur. Thus, germination ability of Stevia seeds can be increased with insect pollination. Otherwise, without cross pollination, Stevia flowers produce light/hollow seeds which don't have germination ability. Many studies have demonstrated that seed yield and viable seed rate increased through insect pollination in many plant species. Midmore and
Rank (2002) reported that intensive bee population (3-5 hives for one hectare) was required for good seed production in Stevia fields. Hof and Lange (1998) determined that the total seed yield of plants without nets was about five times higher than of plants covered with nets in Margherite Africane (Dimorphotheca pluvialis L.) belonging to Asteraceae family like Stevia and they emphasized that Margherite Africane needs pollinator insects for good seed yield. Guayule (Parthenium argentatum) also belongs to Asteraceae family and self-incompatible species like Stevia. In this species, plants pollinated with bee produced at least $150 \%$ more seeds than plants pollinated without bees (Mamood et al., 1990).

The correlation analysis gave important results (Table 2). Significant and positive correlations were found between seed yield per plant and 1000 seeds weight, black/filled seed rate and germination rate, but negative correlation with first germination day.

On the other hand, 1000 seeds weight revealed positive correlation with dark coloured/filled seed rate and germination rate, but negative correlation with first germination day. Dark coloured/filled seed rate showed positive correlation with germination rate, and negative correlation with first germination day. Furthermore, first germination day and germination rate were negatively correlated. Dark coloured seeds are heavier than light/hollow seeds in Stevia (Goettemoeller and Ching, 1999), therefore the increase in dark coloured/filled seed rate caused an increase in seed yield per plant and 1000 seeds weight.

Table 1. The effect of pollination methods on seed yield and germination features

\begin{tabular}{|l|c|c|c|c|c|}
\hline & $\begin{array}{c}\text { Seed yield } \\
\text { per plant } \\
(\mathrm{g})\end{array}$ & $\begin{array}{c}1000 \text { seeds } \\
\text { weight } \\
(\mathrm{g})\end{array}$ & $\begin{array}{c}\text { Dark } \\
\text { coloured/filled } \\
\text { seed rate (\%) }\end{array}$ & $\begin{array}{c}\text { First } \\
\text { germination } \\
\text { day (day) }\end{array}$ & $\begin{array}{c}\text { Germination } \\
\text { rate } \\
(\%)\end{array}$ \\
\hline Open (cross) pollination & $3.636 \mathrm{a}$ & $0.398 \mathrm{a}$ & $78 \mathrm{a}$ & $3 \mathrm{a}$ & $49.0 \mathrm{a}$ \\
\hline Self-pollination (with hand) & $2.064 \mathrm{~b}$ & $0.330 \mathrm{~b}$ & $48 \mathrm{~b}$ & $4 \mathrm{a}$ & $15.4 \mathrm{~b}$ \\
\hline Closed/Control & $2.096 \mathrm{~b}$ & $0.268 \mathrm{~b}$ & $9 \mathrm{c}$ & $6 \mathrm{~b}$ & $2.4 \mathrm{~b}$ \\
\hline LSD & 1.277 & 0.066 & 7.938 & 1.037 & 13.339 \\
\hline
\end{tabular}

In columns, different letters show different means according to Duncan test results at 5\% confidence interval. LSD: Least Significant Difference

Table 2. Correlation co-efficiencies between the factors

\begin{tabular}{|c|c|c|c|c|}
\hline & $\begin{array}{l}\text { Seed yield per } \\
\text { plant }\end{array}$ & $\begin{array}{l}1000 \text { seeds } \\
\text { weight }\end{array}$ & $\begin{array}{c}\text { Dark coloured/filled } \\
\text { seed rate }\end{array}$ & $\begin{array}{c}\text { First germination } \\
\text { day }\end{array}$ \\
\hline 1000 seeds weight & $0.612 *$ & & & \\
\hline Dark coloured/filled seed rate & $0.572^{*}$ & $0.777 * *$ & & \\
\hline First germination day & $-0.593^{*}$ & $-0.547 *$ & $-0.832 * *$ & \\
\hline Germination rate & $0.708 * *$ & $0.779 * *$ & $0.831^{* *}$ & $-0.766 * *$ \\
\hline
\end{tabular}

*and ${ }^{* *}$ : are significantly different at $\mathrm{P}<0.05$ and $\mathrm{P}<0.01$, respectivel 
One of the most important results obtained in present study is correlation between dark coloured/filled seeds rate and germinations features. While dark coloured/filled seed rate was significantly and negatively correlated with first germination day, positive and significant correlation obtained between dark coloured/filled seed rate and germination rate. This result shows that dark coloured/filled seeds should be selected to obtain high germination rate in Stevia. Midmore and Rank (2002) explained that usually dark coloured seeds are fertile whereas infertile seeds are colorless in Stevia. Also, a significant and negative correlation was found between first germination day and germination rate. This information indicated that seeds which have high germination rate have earlier germination ability.

\section{Conclusions}

Stevia is a self-incompatible plant and needs pollinator. Otherwise, Stevia plants produce seeds with low germination rates in case of inadequate pollination conditions. In this study, results showed that cross pollination have positive effects on seed yield and especially dark coloured/filled seed rate. Also, while dark coloured/filled seed rate increased, the germination rate of seeds was found to be much higher. As a result, the bee population should be available in the Stevia fields to produce viable seeds, and also dark coloured/filled seeds should be preferred to grow Stevia seedling.

\section{References}

Brading, P., El-Gabbas, A., Zalat, S., Gilbert, F., 2009. Biodiversity economics: The value of pollination services to Egypt. Egyptian Journal of Biology, 11: 46-51.

Brandle, J. E., Starratt, A.N., Gijzen, M., 1998. Stevia rebaudiana: Its biological, chemical and agricultural properties. Canadian Journal of Plant Science, 78: 527-536.

Cerana, M., 2004. Flower morphology and pollination in Mikania (Asteraceae). Flora, 199:168-177.

Corbet, S.A., Williams, I.H., Osborne, J.L., 1991. Bees and the pollination of crops and wild flowers in the European Community. Bee World, 72:47-59.

Delaplane, K.S., Mayer, D.F., 2000. Crop pollination by bees. CAB International, Oxon, United Kingdom, pp. 344

Goettemoeller, J., Ching, A., 1999. Seed germination in Stevia rebaudiana. In: J. Janick (ed.), Perspectives on new crops and new uses. ASHS Press, Alexandria, VA., pp. 510-511.
Hein, L., 2009. The Economic value of the pollination service, a review across scales. The Open Ecology Journal, 2: 74-82.

Hof, L., Lange, W., 1998. The influence of insect pollination on yield components in Dimorphotheca pluvialis. Genetic Resources and Crop Evolution, 45: 441-446.

Ingrouille, M., Eddie, B., 2006. Plants: Evolution and diversity. Cambridge University, Press, New York.

Isagi, Y., 2011. Significance of single-pollen genotyping in ecological research. In: Y. Isagi and Y. Suyama (eds.), single-pollen genotyping (Chapter 1), Ecological Research Monographs, 1-6. DOI 10.1007/978-4-431-53901-8 1.

Klein, A.M., Müller, C., Hoehn, P., Kremen, C., 2009. Understanding the role of species richness for crop pollination services, In: S. Naeem, D.E. Bunker, A. Hector, M. Loreau, C. Perrings, (ed.), Biodiversity, ecosystem functioning, and human wellbeing-An ecological and economic perspective, Oxford University Press, pp. 195-208.

Kumuda, C.N., 2006. Influence of plant growth regulators and nitrogen on regulation of flowering in stevia (Stevia rebaudiana Bert.). (Master thesis) Department of Crop Physiology College of Agriculture, Dharwad University of Agricultural Sciences, Dharwad.

Madan, S., Ahmad, S., Singh, G.N., Kohli, K., Kumar, Y., Singh, R., Garg, M., 2010. Stevia rebaudiana (Bert.) Bertoni-A review. International Journal of Production Research, 1: 267-286.

Mamood, A.N., Ray, D.T., Waller, G.D., 1990. Seed set in Guayule (Parthenium argentatum, Asteraceae) in relation to insect pollination. Economic Botany, 44(4): 440-444.

Midmore, D.J., Rank, A.H., 2002. A new rural industryStevia to replace imported chemical sweeteners, RIRDC web publication, Project No. UCQ- 16A. https://rirdc.infoservices.com.au/downloads/W02022.pdf (Accessed: 11.01.2013).

Munguía-Rosas, M.A., Ollerton, J., Parra-Tabla, V., 2011. Phenotypic selection on flowering phenology and size in two dioecious plant species with different pollen vectors. Plant Species Biology, 26: 205-212.

Paalhaar, J., Boot, W.J., Van Der Steen, J.J.M., Calis, J.N.M., 2008. In-hive pollen transfer between bees enhances cross-pollination of plants. Proceedings of the section Experimental and Applied Entomology of the Netherlands Entomological Society, 19: 53-58.

Ramesh, K., Singh, V., Ahuja, P.S., 2007. Production potential of Stevia rebaudiana (Bert.) Bertoni. under intercropping systems. Archives of Agronomy Soil Science, 53(4): 443-458.

Yadav, A.K., Singh, S., Dhyani, D., Ahuja, P.S., 2011. A review on the improvement of stevia [Stevia rebaudiana (Bertoni)]. Canadian Journal of Plant Science, 91(1): 1-27. 